Article

\title{
Analysis of Urban Flood Inundation Patterns According to Rainfall Intensity Using a Rainfall Simulator in the Sadang Area of South Korea
}

\author{
Hoje Seong ${ }^{1}$, Dong Sop Rhee ${ }^{1}$ and Inhwan Park ${ }^{2, *(1)}$ \\ 1 Korea Institute of Civil Engineering and Building Technology, 283 Goyangdae-Ro, Ilsanseo-Gu, \\ Goyang-Si 10223, Gyeonggi-Do, Korea; hoje.seong@kict.re.kr (H.S.); dsrhee@kict.re.kr (D.S.R.) \\ 2 Seoul National University of Science and Technology, 232 Gongreung-ro, Nowon-Gu, Seoul 01811, Korea \\ * Correspondence: ihpark@seoultech.ac.kr
}

Received: 26 November 2019; Accepted: 7 February 2020; Published: 9 February 2020

check for updates

\begin{abstract}
An urban flood in the Sadang area located in South Korea was reproduced using a rainfall simulator. The rainfall simulator was developed to be able to demonstrate the rainfall intensity in range of $80-200 \mathrm{~mm} / \mathrm{h}$, and the artificial rainfall was created using 42 full cone type nozzles in the urban model. The uniformity coefficient of the rainfall distribution was $89.5 \%$, which indicates the rainfall simulator achieved the high requirements for spatial uniformity. The flood experiments in the 1/200 scale model of the Sadang area were conducted using the rainfall simulator, and the flood patterns were investigated by changing the rainfall intensity. The rainwater mainly accumulated in the lowland of the crossroad where the entrances to the subway station are located. The flow velocity and the inundation depth were sharply increased until the rainfall intensity became $160 \mathrm{~mm} / \mathrm{h}$. Furthermore, the unstable human activities based on the moment and the friction instabilities also occurred from $160 \mathrm{~mm} / \mathrm{h}$. These results suggest that the study area requires flood damage mitigation facilities considering a rainfall intensity exceeding $160 \mathrm{~mm} / \mathrm{h}$.
\end{abstract}

Keywords: urban flood; rainfall simulator; rainfall intensity; runoff velocity; inundation depth

\section{Introduction}

Rapid increase of urbanization and high-intensity rainfall due to climate change cause an increase in flood damages in urban areas. Seoul is the capital city of South Korea and damages from a big flood originated due to intense rainfall during 26-29 July 2011. In this flood event, the maximum rainfall intensity was recorded as $86 \mathrm{~mm} / \mathrm{h}$ in the Seocho-dong and $113 \mathrm{~mm} / \mathrm{h}$ in the Namhyeon-dong. To prevent severe damages in the future, it is necessary to study vulnerabilities from flood events in the Sadang areas. However, essential data to analyze flood patterns such as flow velocity and inundation depth was not measured in the urban areas. Numerical models were used to reproduce the flood events [1], but it is difficult to do a model validation due to the lack of measurements. Thus, experimental studies are required to reproduce the flood events and provide data for model validations.

Studies to reproduce artificial rainfall have been conducted using a rainfall simulator. Roberts and Klingeman [2] developed a rainfall simulator generated by using seven nozzles arranged in a row, and flood runoff experiments were conducted in a model of a river basin. The rainfall simulator was used for field studies to investigate soil crusting and erosion, and portable rainfall simulators were designed to move the device in the study area [3-5]. Thus, the devices were limited to generating a rainfall intensity of around $100 \mathrm{~mm} / \mathrm{h}$. After that, a rainfall simulator that can reproduce a $180 \mathrm{~mm} / \mathrm{h}$ rainfall intensity was designed to conduct soil erosion studies [6]. This rainfall simulator also can be used to investigate the transport of non-point sources induced by the urban runoff [7]. For urban 
flood experiments, Isidoro et al. [8] adopted a rainfall simulator to investigate the wind-driven rainfall effects to the distribution of flood runoff in a scale model of high-rise buildings. From previous studies, a rainfall simulator is useful to demonstrate the rainfall-runoff process in scale models and field studies. Thus, in this study, a rainfall simulator was designed to demonstrate urban inundation, and a case study was conducted in the Sadang area.

In this study, the research objectives can be summarized as: (1) design of rainfall simulator and validation of uniformity of artificial rainfall distributions; (2) demonstration of flood events in the Sadang area and analysis of flood characteristics from runoff velocity and inundation depth; (3) analysis of vulnerabilities of human activities during flood events in the Sadang area. The rainfall simulator was designed to reproduce the rainfall intensity exceeding the maximum rainfall intensity of the Sadang area for considering extreme cases. The spatial variability of rainfall was examined from the uniformity tests of nozzles. After finishing the validations, flood experiments were conducted in the scaled urban model, and the flood patterns were analyzed according to the rainfall intensity. From the measurements of the runoff velocity and the inundation depth, the flood vulnerabilities were investigated from the moment and the friction instabilities.

\section{Experimental Methods}

\subsection{Design of Rainfall Simulator}

The rainfall simulator was designed to generate uniformly distributed precipitation over a $6 \mathrm{~m} \times 6$ $\mathrm{m}$ area using serially arranged nozzles as shown in Figure 1 . The experimental device consisted of a water supply tank, pipe network to convey a constant flowrate, and nozzles. The artificial rainfall was sprayed from a nozzle arranged on a pipeline placed at $6 \mathrm{~m}$ height. For uniform distribution, 7 nozzles were placed on a line at $0.75 \mathrm{~m}$ intervals and six lines were arranged at $0.75 \mathrm{~m}$ distance after conducting a uniformity test. Not only the arrangements of nozzles but also the selection of the nozzle type affect to the uniform distribution. In this study, the full cone spray nozzle (Model No. 3/8F JUP 03 S303) manufactured by the Ikeuchi was used to design the equipment. Water supply to the nozzle was maintained at a constant pressure and flowrate while the experiments were conducted.

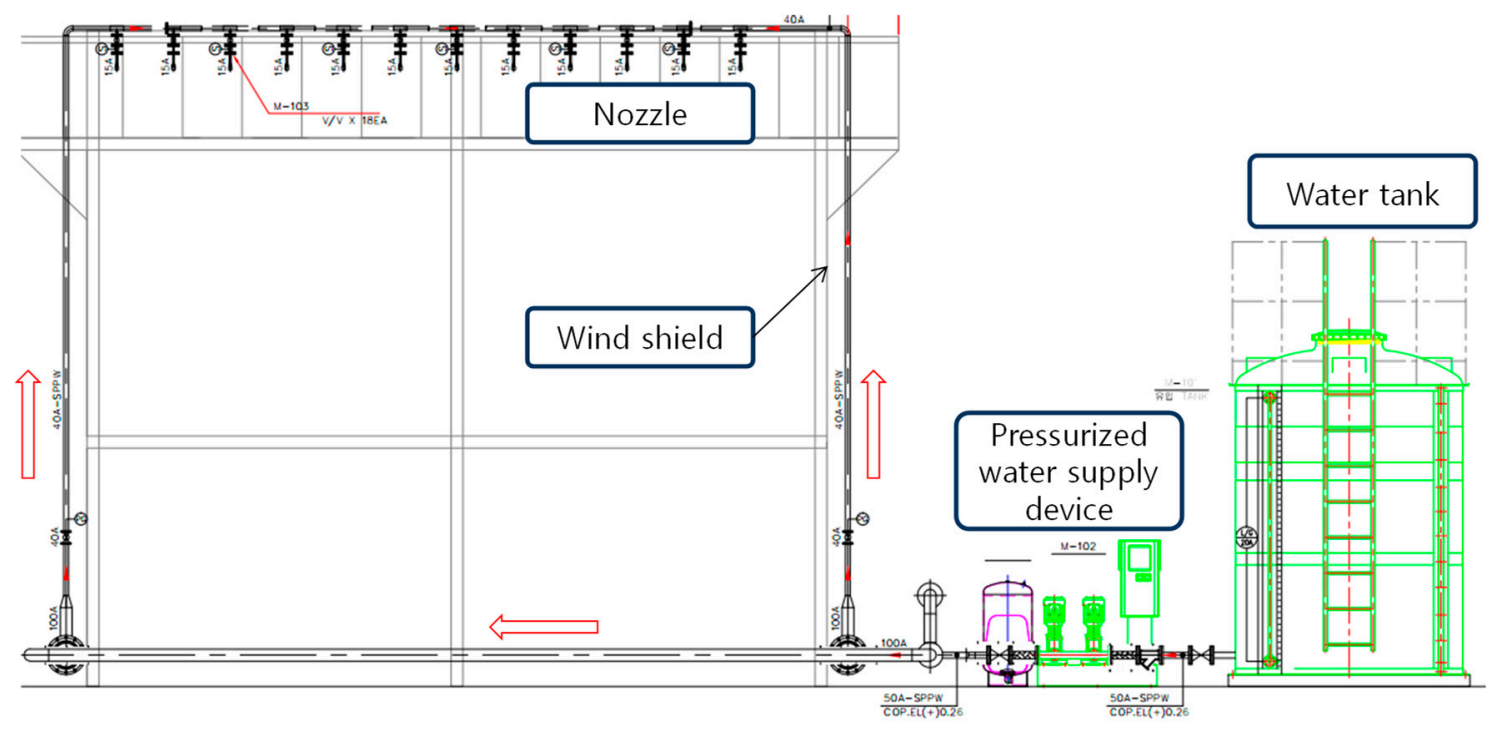

Figure 1. Design of rainfall simulator.

\subsection{Uniformity Tests of Rainfall Distribution}

The uniformity of distributed rainfall from nozzles was tested by using rain gauges as shown in Figure 2. First, a rainfall distribution from a single nozzle (Figure 2a) was measured by arranging rain gauges as shown in Figure 2c, in which nineteen rain gauges were placed under a nozzle. The tests were 
conducted for 42 nozzles installed on the rainfall simulator, and the measurements were repeated four times for $10 \mathrm{~min}$. The measurement data along Sec. A- $\mathrm{A}^{\prime}, \mathrm{B}-\mathrm{B}^{\prime}$, and $\mathrm{C}-\mathrm{C}^{\prime}$ were plotted in Figure $3 \mathrm{a}-\mathrm{C}$. When the rainfall intensity at the center point was $111.0 \mathrm{~mm} / \mathrm{h}$, the rainfall intensity at the gauge between the center point and the outer point was in the range of $25.3-27.1 \mathrm{~mm} / \mathrm{h}$, and the results show a range of $1.9-2.1 \mathrm{~mm} / \mathrm{h}$ at the outer points. Thus, the tests for a single nozzle show an isotropic rainfall distribution, and the repeatability of same rainfall intensity was maintained about $90 \%$ for a single nozzle.

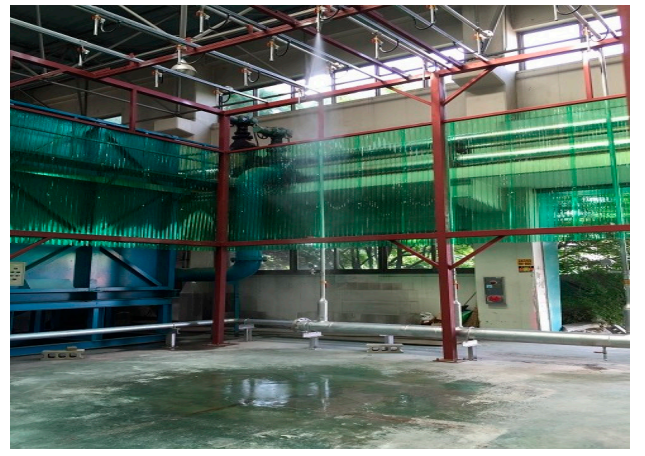

(a)

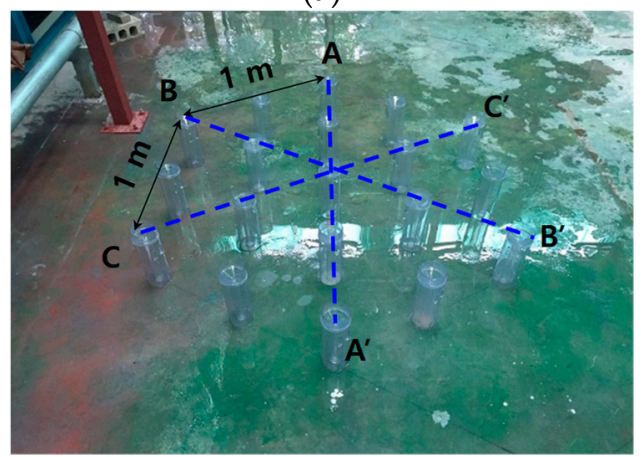

(c)

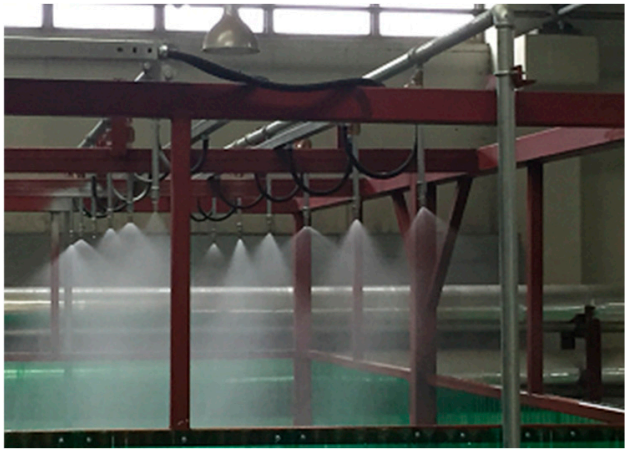

(b)

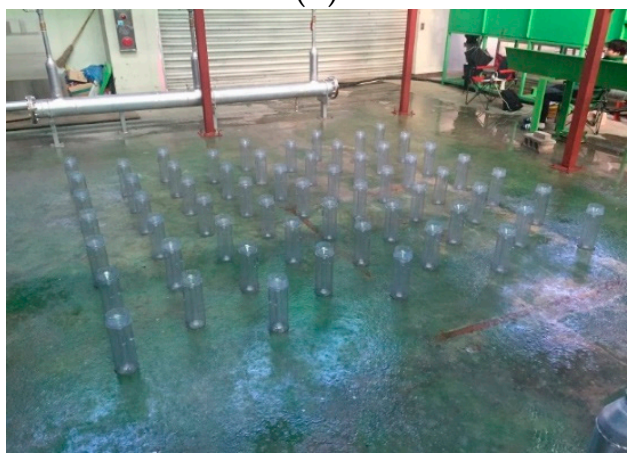

(d)

Figure 2. Arrangements of rain gauges for the uniformity tests: (a) operation for a single nozzle test;

(b) operation for a total nozzle test; (c) single nozzle test; (d) total nozzle test.

The rainfall distribution under the rainfall simulator was measured using 59 gauges as shown in Figure $2 \mathrm{~d}$. Figure $3 \mathrm{~d}$ shows the spatial distribution of the rainfall intensity. The distribution of the rainfall intensity for all nozzles shows the superposition of rainfall distribution for a single nozzle that shows nearly a Gaussian distribution. Thus, the falling limbs were smoothed by the arrangement of nozzles, but a perfect uniformity was not achieved in the entire area. From the rainfall distribution shown in Figure 3d, the spatial uniformity was quantified using the Christiansen's Uniformity Coefficient (CUC) defined as follows [8].

$$
\text { CUC }=1-\frac{\sum_{i=1}^{n}\left|R_{i}-\bar{R}\right|}{n \bar{R}}
$$

where $n$ is the number of rain gauge, $R_{i}$ is depth measured in each rain gauge, and $\bar{R}$ is the average of $R_{i}$. Utility of the CUC was recommended to test the uniformity of rainfall, and the value of CUC is required to be higher than $85 \%$ for high uniformity [9]. In this study, the calculation result of CUC was $89.2 \%$ which achieved the recommended requirements for experiments. 


\subsection{Inundation Simulations in the Sadang Area}

In this study, the Sadang station area in Seoul, South Korea, which was flooded due to intensive rainfall in 2011, was selected to reproduce urban flood events. Figure 4 shows the aerial photo of the Sadang station which is located at the foot of mountains and is a densely populated area. In this area, 14 entrances to the subway station as marked in Figure $4 \mathrm{a}$ are located around the crossroad, and the estimated inundation depth is about $0.8-1.0 \mathrm{~m}$ from the pictures taken during the flood event. The scale of the target area was determined as 1/200 for reproducing the inundation depth over $1 \mathrm{~m}$ in a $800 \mathrm{~m} \times 800 \mathrm{~m}$ area. The urban model size shown in Figure $4 \mathrm{~b}$ was a $4 \mathrm{~m} \times 4 \mathrm{~m}$ area that was appropriate to place within the range of artificial rainfall. Bottom slopes of every road and mountain hills were totally reproduced following the design of the city. In the construction of the buildings and roads in the model, there are some limitations to demonstrate the real city environment. Roads less than $5 \mathrm{~m}$ wide between buildings were neglected in the urban model to eliminate errors induced by the surface tension, and buildings around the roads were grouped as a block. The blocks had the same height and flat roofs to simplify the model. Furthermore, the rainfall infiltration system in both buildings and roads was not considered, because the flood event occurred due to the exceeded capacity of the system. On account of the aforementioned limitations, however, inundation depth would be overestimated by accumulated runoff of the flow area and storages in a building.

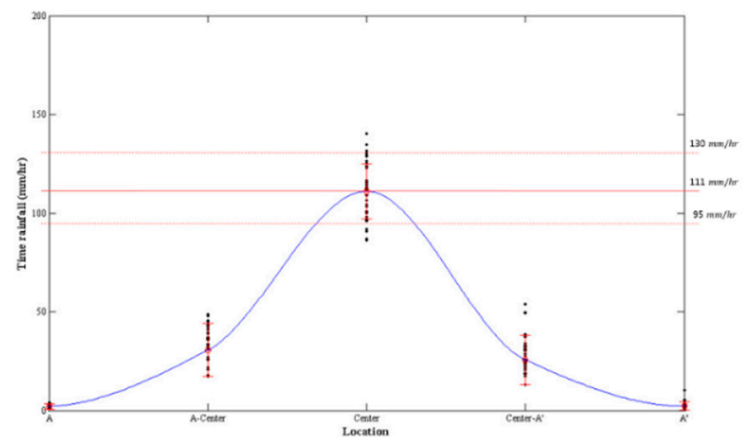

(a)

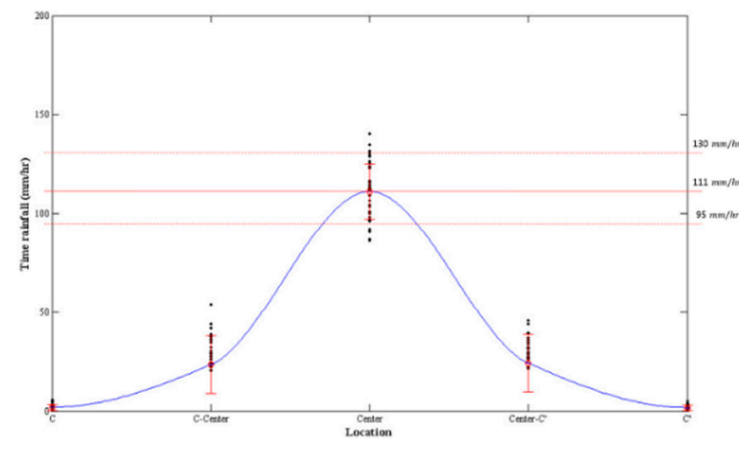

(c)

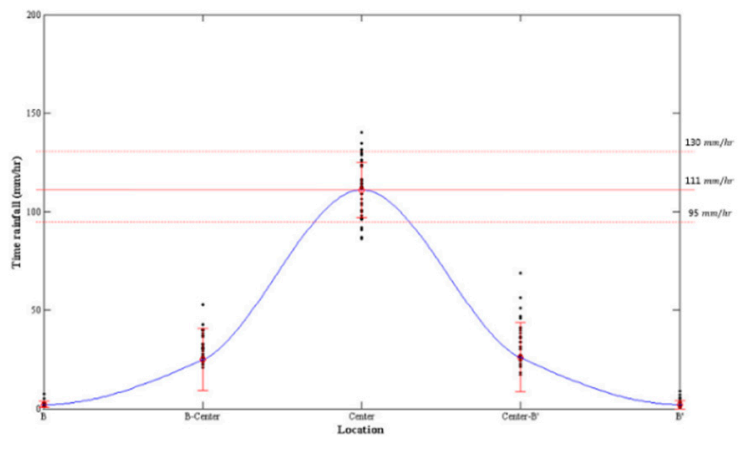

(b)

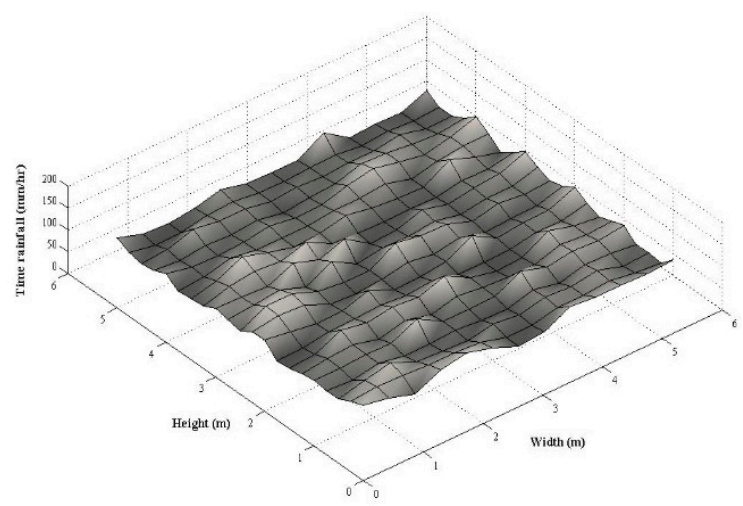

(d)

Figure 3. Results of the uniformity tests: (a) Sec. A-A' for single nozzle test; (b) Sec. B-B' for single nozzle test; (c) Sec. C-C $C^{\prime}$ for single nozzle test; (d) rainfall distribution for entire area.

The pressurized water supply device manipulated the rainfall intensity on the model, and thus, the rainfall intensity was defined from the pressure values. As described in Table 1, the runoff from the model was measured under a constant pressure and the rainfall intensity was calculated for the prototype. When the pressure changed from 1.0 bar to 3.0 bar, which is the possible range of the water supply system, the rainfall intensity was in range of $80-200 \mathrm{~mm} / \mathrm{h}$. The range of rainfall intensity in the 
model is possible to reproduce the rainfall event in 2011 and extraordinary, extreme flood cases. Under the rainfall conditions, inundated patterns were observed by measuring the runoff velocity and the inundation depth.

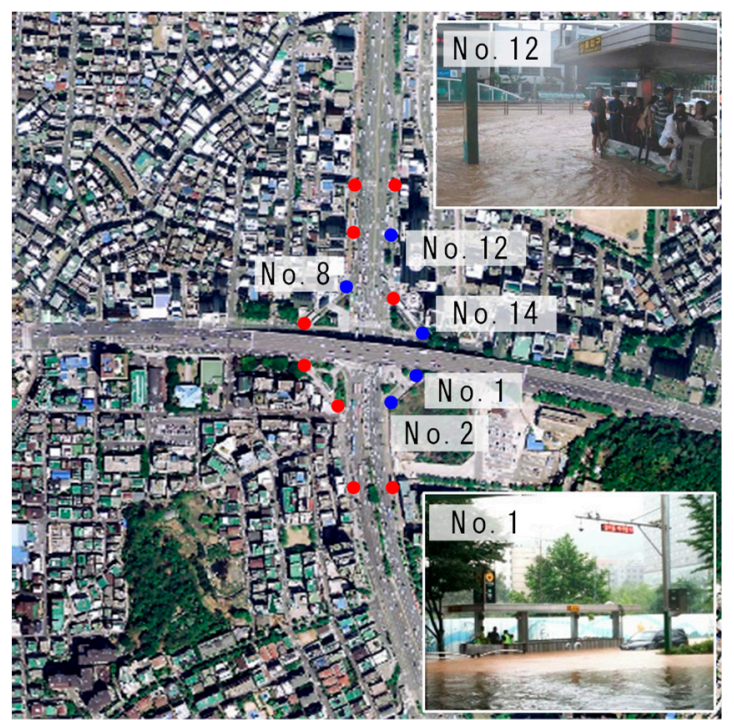

(a)

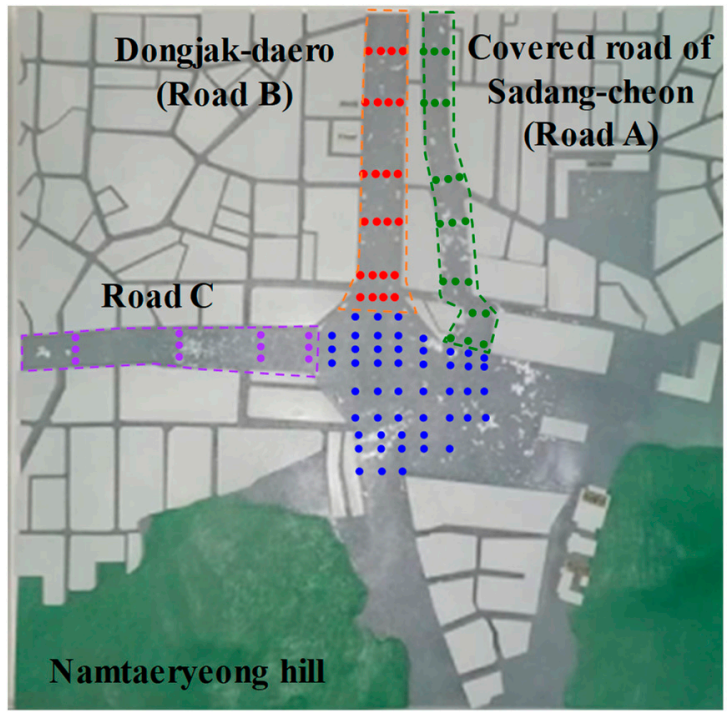

(b)

Figure 4. Descriptions of Sadang-Cheon area: (a) aerial photo of study area; (b) scale model.

Table 1. Rainfall intensity change according to manipulated pressure of the water supply system.

\begin{tabular}{cc}
\hline Pressure of Water Supply System (bar) & Rainfall Intensity $(\mathbf{m m} / \mathbf{h})$ \\
\hline 1.0 & 80 \\
1.5 & 130 \\
2.0 & 160 \\
2.5 & 185 \\
3.0 & 200 \\
\hline
\end{tabular}

\subsection{Measurements of Flood Characteristics}

The flood patterns in the Sadang station were analyzed by measuring flow velocity. The rainfall intensity for the flood simulations followed the conditions of Table 1. Even under the maximum rainfall intensity, the maximum inundation depth in the urban model was less than $1.5 \mathrm{~cm}$. Thus, a contact-type measurement equipment is not appropriate to measure velocity. Furthermore, a measuring system under artificial rainfall can be disturbed by rainfall distributions. For these reasons, the flow characteristics on roads were measured using LSPIV (Large-Scale Particle Image Velocimetry), which is one of the non-contact type measurement methods. A high-frequency camera was used for the LSPIV analysis, and the camera was installed on the roof of the rainfall simulator. $1920 \times 1080$ size images were captured in 60 frames per second, and each image contained the whole area of the urban model. From the aforementioned method, surface velocity of the model was analyzed using Dynamic Studio developed by Dantec Dyanamics. The software was used for several research projects to analyze flow velocity [10-12]. Figure 5a shows the velocity vector analyzed using the Dynamic Studio software. The inundation depth in the model was measured using a tape ruler attached to a $2 \mathrm{~m}$ long rod as shown in Figure 5b. Using the equipment, the inundation depth could be measured by minimizing disturbances in the rainfall distribution. The measurement points for the inundation depth were described in Figure $4 \mathrm{~b}$. 


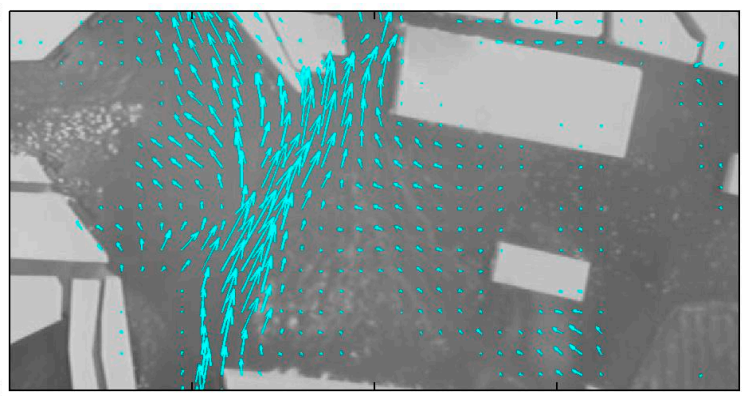

(a)

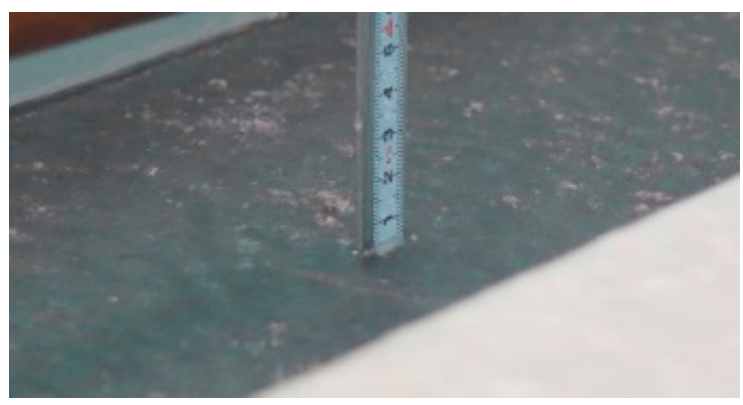

(b)

Figure 5. Flow measurements using Large-Scale Particle Image Velocimetry (LSPIV) and tape ruler: (a) runoff velocity measurement; (b) inundation depth measurement.

Unfortunately, field observations were not conducted during the flood events in 2011. Thus, the inundation depth reproduced in this study was compared using photos shown in Figure 4a taken near the entrance of the Sadang station during the flood. From the photos, the inundation depth is estimated at about $0.75 \mathrm{~m}$ near entrance No. 12 because the flood level exceeded the height of stairs, which have $0.25 \mathrm{~m}$ in average for each step. In the case near entrance No. 1, the flood level rose to the height of a tire which is in range of $0.65-0.76 \mathrm{~m}$ according to the type of vehicle. The inundation depth measured in the condition of $80 \mathrm{~mm} / \mathrm{h}$ was $1.0 \mathrm{~m}$ and $0.8 \mathrm{~m}$ near the entrance No. 1 and 12, respectively. These results indicate that the measurements contain about $14 \%-33 \%$ errors even though the exact comparisons were not available due to the lack of field records. The discrepancies against to the observations through the pictures seems to be induced by the aforementioned limitations of the urban model.

\section{Urban Inundation Simulation Using the Rainfall Simulator}

\subsection{Runoff Descriptions}

The runoff patterns against rainfall intensities were analyzed from the runoff velocity and the inundation depth. Every measured data was converted to real scale values based on the Froude similitude defined as

$$
\mathrm{Fr}_{r}=\frac{v_{r}}{\sqrt{h_{r}}}=1
$$

where $\mathrm{Fr}_{r}$ is the Froude number ratio defined as $1 ; v_{r}$ is the velocity ratio; $h_{r}$ is the length scale defined as $1 / 200$ in this study. Figure 6 shows time-averaged contours of the flow velocity according to rainfall intensity. The slope of the target area gradually decreased toward the north from the Namtaeryeong hill in the south. Thus, the flow accumulated in relatively low lands where the crossroad, Road A (Covered road over the Sadang-cheon), and Road B (Dongjak-daero) are located. The rainwater from the southern hill was rushed to the crossroad which has eight entrances to the underground space of Sadang station, and the velocity increased especially on the east side of the crossroad. The flood water running off the crossroad divided onto Road A and Road B. The rainwater from the residential areas also flowed to these roads. Thus, the flow velocity locally increased near the confluence of the main roads and the residential areas. The elevation on Road $C$ is relatively higher than other areas, and the flow velocity was not observed because the inundation depth on this road was not high enough to transport particles for the LSPIV analysis. The aforementioned flow characteristics can be clearly observed according to increase of rainfall intensity. 


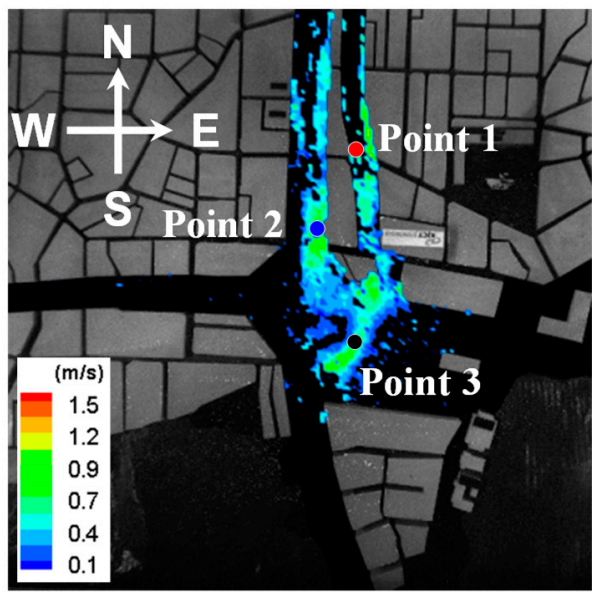

(a)

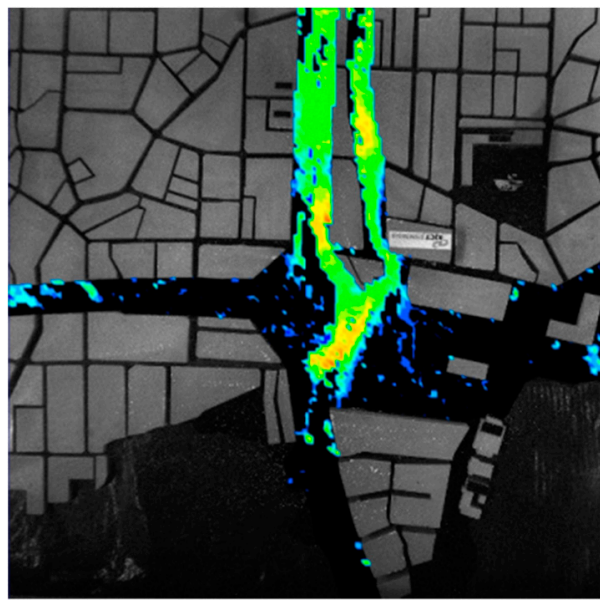

(c)

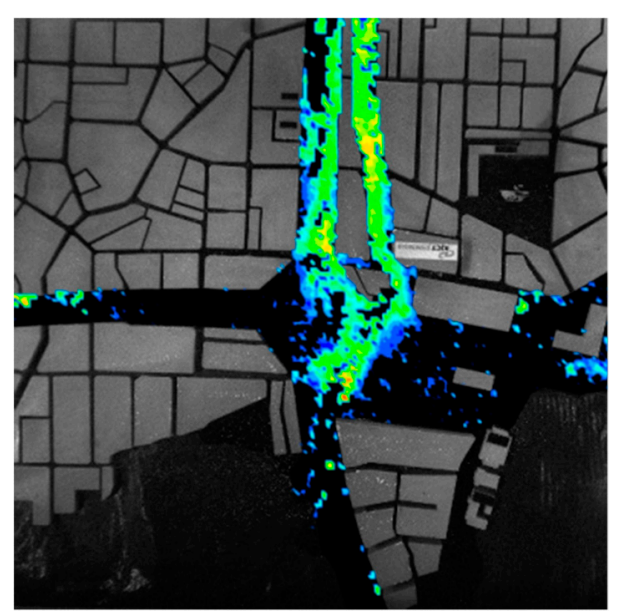

(b)

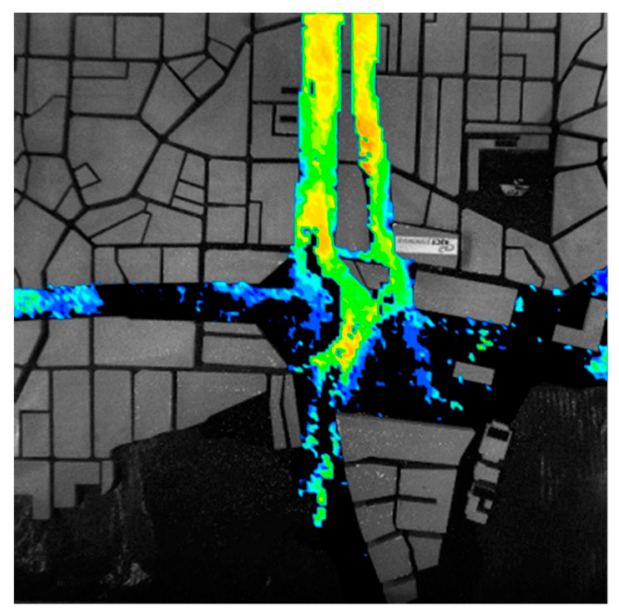

(d)

Figure 6. Runoff velocity distributions according to rainfall intensity: (a) $80 \mathrm{~mm} / \mathrm{h}$; (b) $130 \mathrm{~mm} / \mathrm{h}$; (c) $160 \mathrm{~mm} / \mathrm{h}$; (d) $185 \mathrm{~mm} / \mathrm{h}$.

The maximum velocity on Roads A and B occurred at the points depicted in Figure 6a. Point 1 is a confluence of Road A and a small street connected from the residential area. The flow direction between the two roads have an acute angle, and thus the flow velocity was more accelerated than other confluences. In case of point 2 , the point is located where the width of the corridor for rainwater abruptly decreased the flow onto Road B from the crossroad. In addition, a structure of the entrance of the Sadang station near point 2 further decreased the flow area, and the runoff velocity increased more than another region of Road B. Point 3 is at the bottom of the mountain hill and the relatively steep slope in the crossroad caused the increase of the runoff velocity. The velocity at point 3 rarely increased when the rainfall intensity was over than $160 \mathrm{~mm} / \mathrm{h}$ because the inundation depth sharply rose.

Figure 7 shows distributions of the measured inundation depth according to the rainfall intensity. From the velocity measurement results, one can know that most flood accumulated in the crossroad and Roads A and B. The inundation depth also increased in these three regions. The eastern part of the crossroad was more inundated than the western region. The depth on Road A was higher than that on Road B due to the narrower road width. Previous research conducting numerical simulations in the Sadang area also show that the inundation depth increased through the crossroad and Roads A and $\mathrm{B}$ [1]. They concluded that the flood in the crossroad was caused by the rainwater flowing from the mountain hill and insufficient sewer system capacity. The depth slowly increased between $80 \mathrm{~mm} / \mathrm{h}$ 
and $130 \mathrm{~mm} / \mathrm{h}$. When the rainfall intensity exceeded $160 \mathrm{~mm} / \mathrm{h}$, the inundation depth in the crossroad and Road A noticeably increased, and then the patterns turned to a slow rise again.

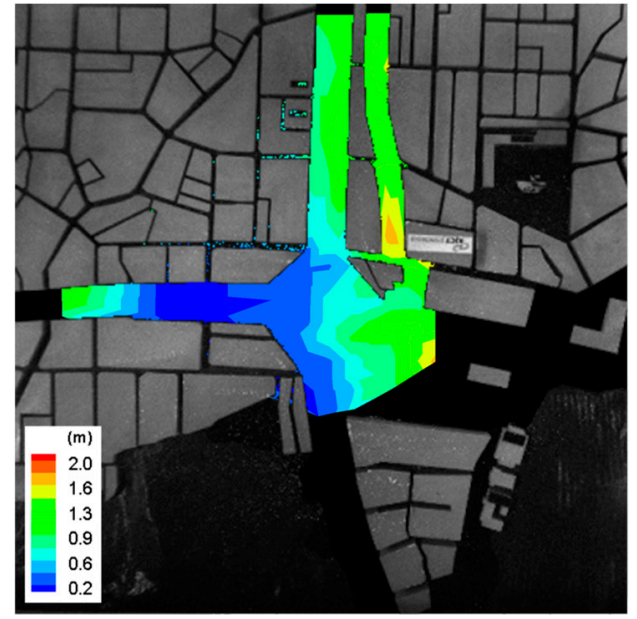

(a)

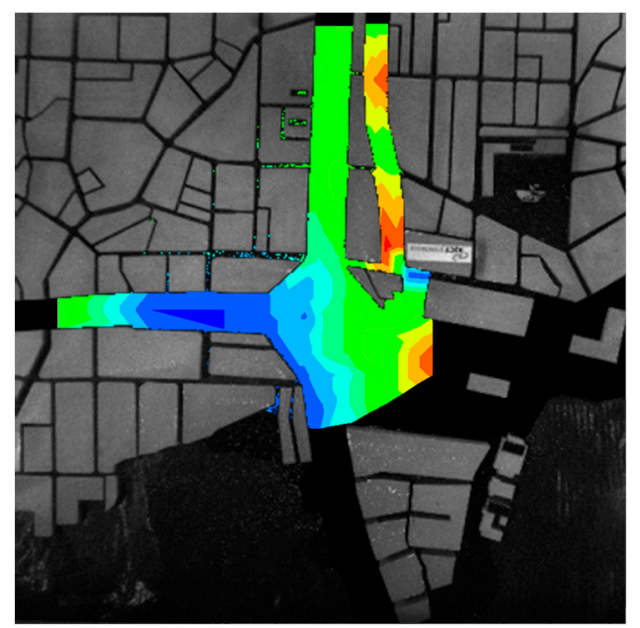

(c)

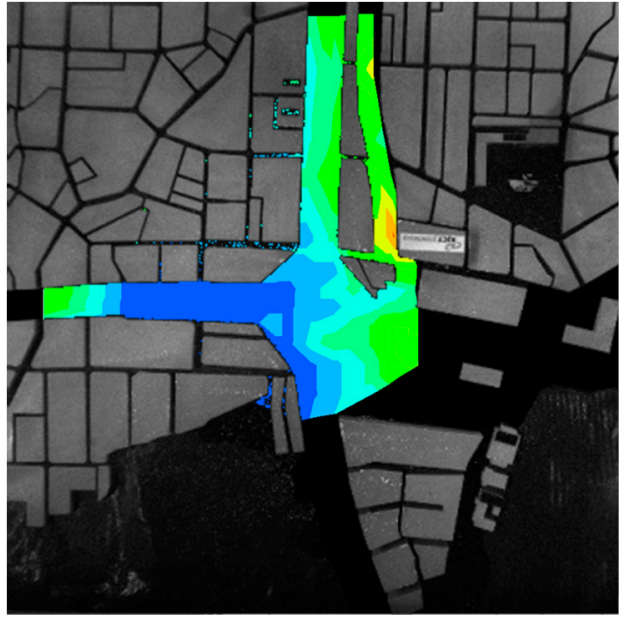

(b)

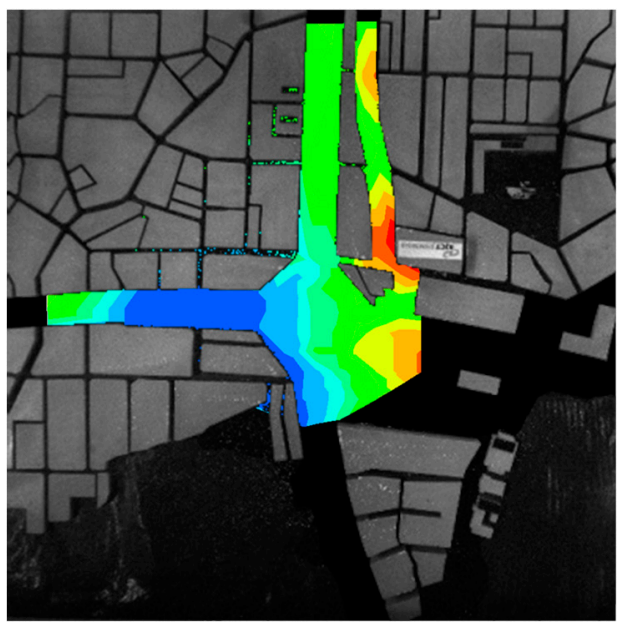

(d)

Figure 7. Inundation depth changes according to rainfall intensity: (a) $80 \mathrm{~mm} / \mathrm{h}$; (b) $130 \mathrm{~mm} / \mathrm{h}$; (c) $160 \mathrm{~mm} / \mathrm{h}$; (d) $185 \mathrm{~mm} / \mathrm{h}$.

\subsection{Analysis of Flood Vulnerabilities}

The inundation depth was compared at three points, which were depicted in Figure 6a. The measured depth and the runoff velocity at the same points was plotted in Figure 8. As can be seen in the inundation depth distributions, the depth shows a small increment in range of $80-130 \mathrm{~mm} / \mathrm{h}$. When the rainfall intensity was above $160 \mathrm{~mm} / \mathrm{h}$, the inundation depth significantly increased, and the depth slowly increased again. These flooding patterns affect the runoff velocity, and there were small increments in the velocity in the range of $160-200 \mathrm{~mm} / \mathrm{h}$. From these results, the threshold rainfall intensity increased flood damage due to a rapid increase of inundation depth and runoff velocity. Especially, the inundated properties of point $C$ in the crossroad were more sensitive to changes of rainfall intensity than other points. Thus, the inundation depth at each the subway station entrance located in the crossroad was compared in Figure 9 according to the rainfall intensity. The results show that the inundation depth at entrance No. 1 shows the largest variations and the deepest depth caused by the increase of the rainfall intensity. Entrance No. 14, located in the eastern part of the crossroad, also shows large increments in the inundation depth when the rainfall intensity 
was $160 \mathrm{~mm} / \mathrm{h}$. The eastern part of the crossroad has a relatively low bed elevation, and the region was severely flooded by the flow runoff from the mountain hill.

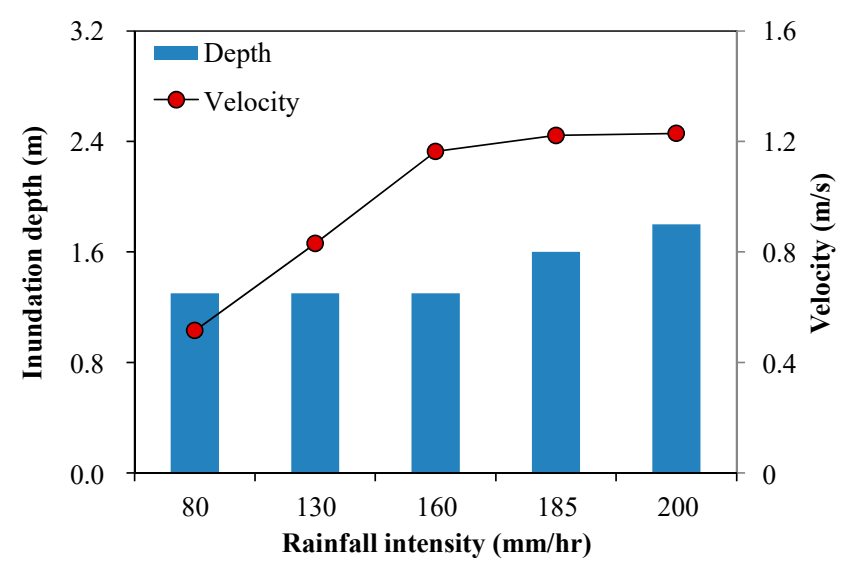

(a)

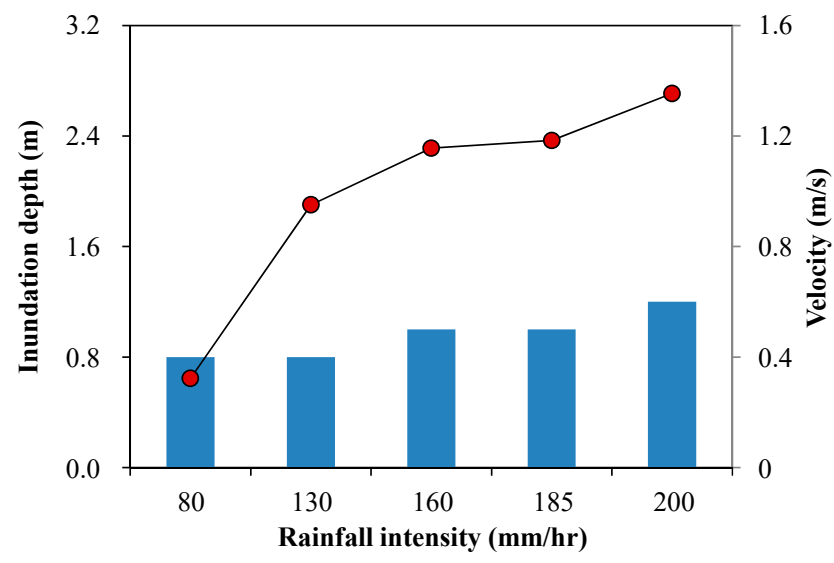

(b)

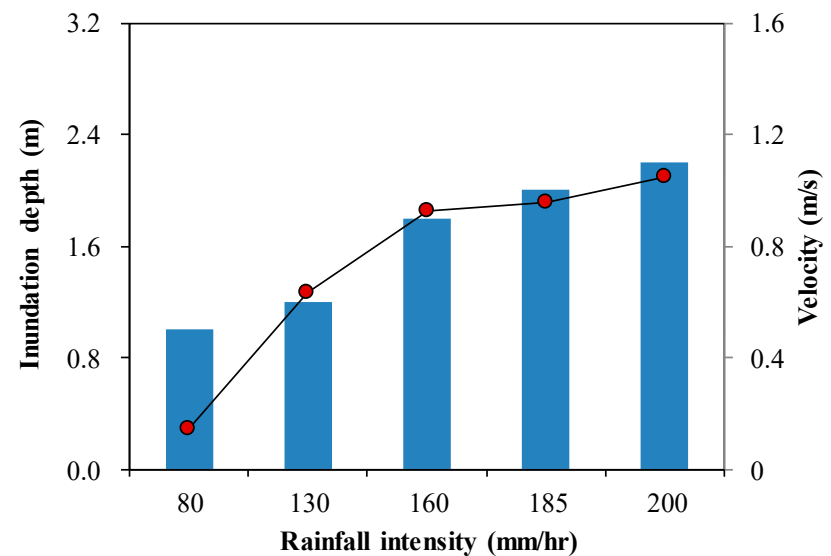

(c)

Figure 8. Velocity and inundation depth against rainfall intensity: (a) point A; (b) point B; (c) point C. 


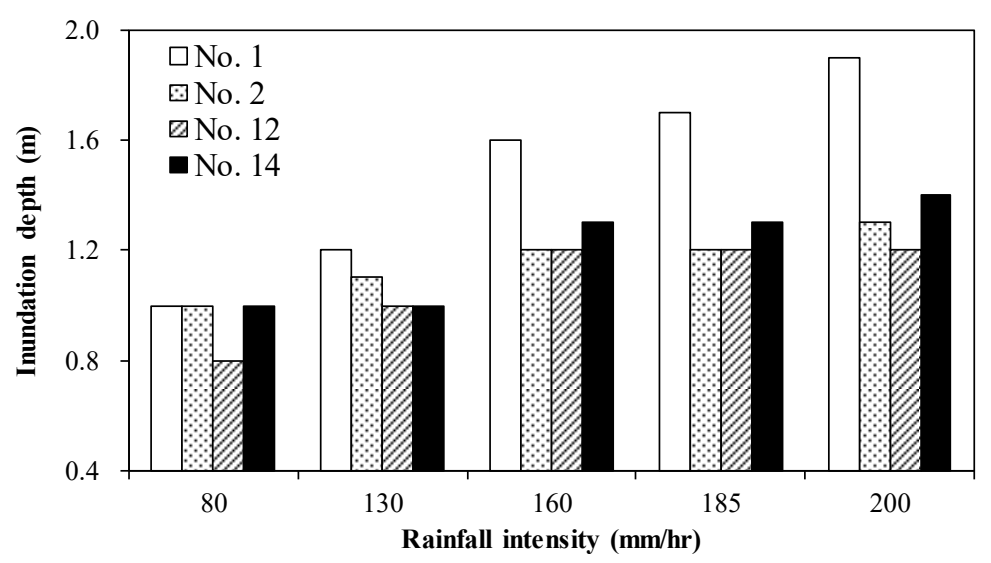

Figure 9. Inundation depth near the subway station entrance.

The vulnerability from the flood events was evaluated using the moment instability $\left(h v_{c}\right)$ and the friction instability $\left(h v_{c}^{2}\right)$ as follows [13].

$$
\begin{gathered}
h v_{c}=\sqrt{\frac{2 m g \cos \alpha L}{C_{D} B \rho}}=C_{M} \sqrt{m} \\
h v_{c}^{2}=\frac{2 \mu g}{C_{D} B \rho} m=C_{F} m
\end{gathered}
$$

where $m$ and $L$ is the mass and height of standard adult male, respectively; $\alpha$ is the person's angle to flowing direction; $C_{D}$ is the drag coefficient; $B$ is the body width exposed normal to the flow; $\rho$ is the density of water; $C_{M}$ is the moment coefficient; $\mu$ is the friction coefficient; $C_{F}$ is the friction coefficient. From Equations (3) and (4), threshold values of runoff velocity $\left(v_{c}\right)$ and inundation depth $\left(h_{c}\right)$ for human safety can be achieved when $h v_{c}$ equals to $h v_{c}^{2}$ as follow.

$$
\begin{gathered}
h_{c}=\frac{C_{M}^{2}}{C_{F}} \\
v_{c}=\frac{C_{F} m^{0.5}}{C_{M}}
\end{gathered}
$$

The threshold values $\left(h_{c}, v_{c}\right)$ in conditions of standard adult male in South Korea who has $L=174 \mathrm{~cm}, m=76 \mathrm{~kg}, C_{D}=1.1$ and $B=0.4 \mathrm{~m}$ and on a concrete covered road ( $\mu=0.5$ [14]) were calculated by changing $\alpha\left(0-90^{\circ}\right)$ and plotted in Figure 10. In Figure 10, the measurement points shown in Figures 8 and 9 were also plotted to evaluate the human instability from floods in the study area. A symbol marked over the instability boundary indicates that a person at the point is in danger to be toppled or sliding due to runoff. As can see in the figure, point 1 on Road B was the most vulnerable because the data was plotted in the unstable area when the rainfall intensity exceeded $160 \mathrm{~mm} / \mathrm{h}$ that is relatively lower than other areas. In other cases, points 2 and 3 were included in the unstable condition when the rainfall intensity is over than $185 \mathrm{~mm} / \mathrm{h}$ and $200 \mathrm{~mm} / \mathrm{h}$, respectively. Among the subway station entrances, only entrance No. 1 was marked above the boundary when the rainfall intensity was $200 \mathrm{~mm} / \mathrm{h}$. From these results, it can be said that instabilities for human activities during flood events would mainly occur on Road B. Furthermore, Road B is a densely populated area, which is occupied by parking lots and business buildings. Therefore, complementary facilities such as the underground storage and drainage system capacities in this area are required to be designed to endure over at least $160 \mathrm{~mm} / \mathrm{h}$. 


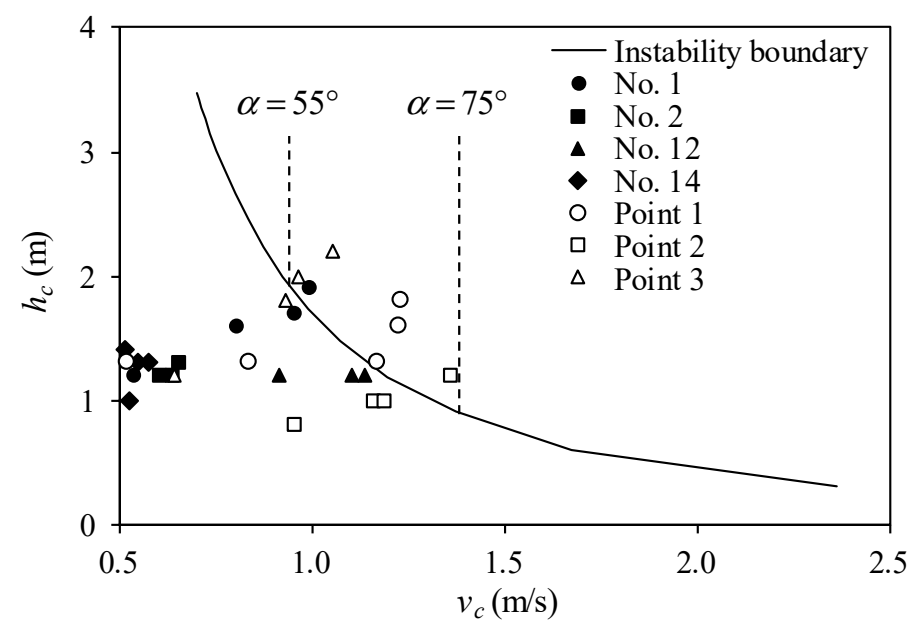

Figure 10. Plots of the instability boundary against to inundation depth and runoff velocity.

\section{Conclusions}

In this research, urban flood experiments were conducted using the rainfall simulator. The rainfall simulator was designed to demonstrate rainfall intensity in range of $80-200 \mathrm{~mm} / \mathrm{h}$, and the full cone nozzle was adopted to spray uniform raindrops. The uniformity of rainfall distribution was tested by measuring the volume of rainwater for a single nozzle and entire nozzles. The single nozzle test results showed that the rainfall intensity was identically reproduced in all nozzles, and the rainfall intensity decreased by distance from the center point in a Gaussian-like distribution. In the case of the entire nozzle tests, even though the spatial distribution of rainfall intensity shows some irregularities, the uniformity coefficient shows $89.2 \%$, which was satisfied highly recommended standard.

Using the rainfall simulator, flood experiments were conducted in the 1/200 scale model of the Sadang station by changing the rainfall intensity. The model has limitations that the sewer systems were neglected, and small buildings were grouped as a block. Thus, the measured inundation depth in the model tended to be overestimated compared to the real flood that occurred in 2011. The experimental results show that the rainwater mainly accumulated in the eastern part of the crossroad in which the entrances to the subway station are located. The flooded water in the crossroad flowed to two main roads that connect the crossroad and the relatively small road across the residential area. The flow velocity and inundation depth noticeably increased until the rainfall intensity reached to $160 \mathrm{~mm} / \mathrm{h}$ and then slowly increased in the higher rainfall intensity.

The quantitative analysis according to change of rainfall intensity was conducted by comparing inundation depth and runoff velocity at representative points. The runoff velocity at Roads $A$ and $B$ significantly rose between $80-160 \mathrm{~mm} / \mathrm{h}$, while the inundation depth slowly increased. In the case of the subway station entrance, the inundation depth at the entrance No. 1 shows the highest values, and the results indicate that a cut-off wall is necessary to prevent rainwater flowing into the underground space. Furthermore, the vulnerabilities of human activities during flood events were evaluated using the moment and the friction instabilities. The analysis results show that human activities at point 1 located on Road B are the most vulnerable compared to other areas because the inundation depth and the runoff velocity exceeded the instability boundary of $160 \mathrm{~mm} / \mathrm{h}$. From these results, the Sadang area is required to prepare the sewer systems or underground storages to endure a flood exceeding $160 \mathrm{~mm} / \mathrm{h}$ rainfall intensity. Furthermore, city development strategies need to pursue a decrease in impermeable areas.

Author Contributions: Conceptualization, D.S.R.; experiments and analysis, H.S. and I.P.; writing—original draft preparation, H.S.; writing-review and editing, I.P.; supervision, D.S.R.; project administration, D.S.R. All authors have read and agree to the published version of the manuscript.

Funding: This research was funded by the Korea Institute of Civil Engineering and Building Technology. 
Acknowledgments: This research was funded by the project "Effects of and solutions for the sophisticated urban geometric characteristics on the increased urban flooding damages" of the Korea Institute of Civil Engineering and Building Technology.

Conflicts of Interest: The authors declare no conflict of interest.

\section{References}

1. Lee, S.; Noh, S.J.; Jang, C.; Rhee, D.S. Simulation and analysis of urban inundation using the integrated 1D-2D urban flood model. J. Korea Water Resour. Assoc. 2017, 50, 263-275. (In Korean)

2. Cerda, A.; Ibanez, S.; Calvo, A. Design and operation of a small and portable rainfall simulator for rugged terrain. Soil Tech. 1997, 11, 163-170. [CrossRef]

3. Abudi, I.; Carmi, G.; Berliner, P. Rainfall simulator for field runoff studies. J. Hydrol. 2012, 6, 76-81. [CrossRef]

4. Chouksey, A.; Lambey, V.; Nikam, B.R.; Aggarwal, S.P.; Dutta, S. Hydrological modelling using a rainfall simulator over an experimental hillslope plot. Hydrology 2017, 4, 17. [CrossRef]

5. Polyakov, V.; Stone, J.; Collins, C.H.; Nearing, M.A.; Paige, G.; Buono, J.; Gomez-Pond, R.-L. Rainfall simulation experiments in the southwestern USA using the Walnut Gulch rainfall simulator. Earth Syst. Sci. Data 2018, 10, 19-26. [CrossRef]

6. Mammon, A.A.; Jahan, S.; He, X.; Joergensen, N.E.; Rahman, A. First flush analysis using a rainfall simulator on a micro catchment in an arid climate. Sci. Total Environ. 2019, 693, 133552. [CrossRef] [PubMed]

7. Isidoro, J.M.G.P.; Lima, J.L.M.P.; Leandro, J. Influence of wind-driven rain on the rainfall-runoff process for urban areas: Scale model of high-rise buildings. Urban Water J. 2012, 9, 199-210. [CrossRef]

8. Solomon, K.H. Yield related interpretations of irrigation uniformity and efficiency measures. Irrig. Sci. 1984, 5, 161-172. [CrossRef]

9. Maroufpoor, E.; Faryabi, A.; Ghamarnia, H.; Moshrefi, G. Evaluation of uniformity coefficients for sprinkler irrigation systems under different field conditions in Kurdistan Province (Northwest of Iran). Soil Water Res. 2010, 5, 139-145. [CrossRef]

10. Corvaro, F.; Paroncini, M. The Natural Convective Heat Transfer in a Partially Divided Enclosure: A Study on the Influence of the Source Position. J. Thermodyn. 2009, 2009, 1-10. [CrossRef]

11. Al-Mamari, M.M.; Kantoush, S.A.; Kobayashi, S.; Sumi, T.; Saber, M. Real-Time Measurement of Flash-Flood in a Wadi Area by LSPIV and STIV. Hydrology 2019, 6, 27. [CrossRef]

12. Gautam, P.; Eldho, T.I.; Mazumder, B.S.; Behera, M.R. Experimental study of flow and turbulence characteristics around simple and complex piers using PIV. Exp. Therm. Fluid Sci. 2019, 100, 193-206. [CrossRef]

13. Jonkman, S.; Penning-Rowsell, E. Human Instability in Flood Flows1. JAWRA J. Am. Water Resour. Assoc. 2008, 44, 1208-1218. [CrossRef]

14. Endoh, K.; Takahashi, S. Numerically modeling personnel danger on a promenade breakwater due to overtopping waves. In Proceedings of the 24th International Conference, Kobe, Japan, 23-28 October 1994; ASCE: New York, NY, USA, 1995.

(C) 2020 by the authors. Licensee MDPI, Basel, Switzerland. This article is an open access article distributed under the terms and conditions of the Creative Commons Attribution (CC BY) license (http://creativecommons.org/licenses/by/4.0/). 